\title{
VIABILIDADE ECONÔMICA EM UM SISTEMA DE PRODUÇÃO DO CULTIVO DE TILÁPIA: UM ESTUDO DE CASO EM UMA PROPRIEDADE RURAL
}

\author{
ROCHA, Geneci da Silva Ribeiro ${ }^{1}$ \\ KUCHAK, Maielen Lambrecht ${ }^{2}$ \\ BIGUELINI, Daniela ${ }^{3}$ \\ ROCHA, Patrício Duarte ${ }^{4}$ \\ OLIVEIRA, Letícia de ${ }^{5}$ \\ LAGO, Adriano ${ }^{6}$
}

Recebido em: 2019.07 .05

Aprovado em: 2020.02.01

ISSUE DOI: $10.3738 / 1982.2278 .3670$

\begin{abstract}
RESUMO: O objetivo desse estudo foi analisar a viabilidade econômica do cultivo de Tilápia do Nilo em um sistema de produção semi-intensivo em uma propriedade no interior do noroeste do Rio Grande do Sul. Foi realizada uma pesquisa de campo, com o acompanhamento das atividades realizadas na propriedade para a obtenção dos dados e informações relevantes ao estudo. Por meio dos custos e receitas da propriedade foram calculados alguns indicadores considerados essenciais como: Valor Presente Líquido, Payback, Taxa Interna de Retorno e Índice de Lucratividade. Ao final do estudo os índices calculados, apresentaram resultados positivos de viabilidade econômica para a propriedade rural, por ser um projeto de longo prazo, são necessários cinco anos para ter retorno sobre o valor investido, a partir desse período, a atividade é lucrativa. Este estudo apresenta bons resultados para todos os índices calculados, tanto o VPL e a TIR resultaram em valores positivos indicando que o cultivo de tilápias remunerará mais que a taxa mínima esperada pela propriedade rural.
\end{abstract}

Palavras-chave: Viabilidade econômica. Piscicultura. Tilápia. Taxa Interna de Retorno. Valor Presente Líquido.

\section{ECONOMIC FEASIBILITY IN A TILAPIA CULTIVATION PRODUCTION SYSTEM: A CASE STUDY ON A RURAL PROPERTY}

\begin{abstract}
SUMMARY: The objective of this study was to analyze the economic viability of Nile Tilapia cultivation in a semiintensive production system at a farm in the northwestern interior of Rio Grande do Sul. A field survey was carried out, to obtain data and information relevant to the study. Through the costs and revenues of the property were calculated some indicators considered essential as: Net Present Value, Payback, Internal Rate of Return and Profitability Index. At the end of the study, the calculated indices presented positive results of economic viability for rural property, since it is a long-term project, it takes five years to have a return on the amount invested. From that period, the activity is profitable. This study presents good results for all calculated indices, both NPV and IRR resulted in positive values indicating that tilapia cultivation will pay more than the minimum rate expected by rural property.
\end{abstract}

Keywords: Economic viability. Pisciculture. Tilapia. Internal Rate of Return. Net Present Value.

\footnotetext{
${ }^{1}$ Administradora, Especialista em Gestão Pública, Mestranda no Programa de Pós Graduação em Agronegócios Universidade Federal do Rio Grande do Sul.

${ }^{2}$ Administradora, Mestranda no Programa de Pós Graduação em Agronegócios - Universidade Federal do Rio Grande do Sul

${ }^{3}$ Administradora, Universidade Federal de Santa Maria

${ }^{4}$ Técnico em Agropecuária, Matemático - Universidade Federal de Pelotas

${ }^{5}$ Administradora, Docente no Departamento de Economia e Relações Internacionais e no Programa de Pós - Graduação em Agronegócio na Universidade Federal do Rio Grande do Sul.

${ }^{6}$ Agrônomo, Professor Associado I no Departamento de Administração e no Programa de Pós Graduação em Agronegócio e Vice-Diretor do Campus de Palmeira das Missões da Universidade Federal de Santa Maria.
} 


\section{INTRODUÇÃO}

A aquicultura tem sido responsável pelo grande crescimento no fornecimento de peixes para o consumo humano, este consumo de peixes tem reforçado as dietas dos seres humanos por se tratar de uma alimentação diversificada e nutritiva (FAO, 2016). Diante disso, a FAO (2016, p.4) afirma que "o peixe é rico em gorduras insaturadas e fornece benefícios para a saúde na proteção contra doenças cardiovasculares. Sua carne também ajuda o desenvolvimento infantil do cérebro e sistema nervoso".

Schulter e Vieira Filho (2017) destaca que a pesca é a atividade que se baseia na retirada de recursos pesqueiros do ambiente natural, e a aquicultura é o cultivo, normalmente em um espaço confinado e controlado, de organismos aquáticos, tais como peixes, crustáceos, moluscos, algas, répteis e qualquer outra forma de vida aquática de interesse econômico produtivo. Como, por exemplo, o cultivo de tilápias pode ser desenvolvida ao mesmo tempo com a agricultura, uma vez que pode ser feito o uso das terras que são inadequadas para outros cultivos, "desde que conte com uma fonte de água compatível, isso torna a piscicultura uma atividade interessante para o pequeno e médio produtor rural por complementar-lhe a renda e proporcionar-lhe uma alimentação sadia" (FIGUEIREDO; VALENTE; 2008, p.05). Portanto, torna-se indispensável a aplicabilidade do sistema semi-intensivo.

Nos últimos anos a produção nacional avançou significativamente e posicionou o Brasil entre os maiores produtores de tilápia do mundo. O mercado interno aumentou o consumo de pescados, segurando, de um lado, as importações, e aproveitando, de outro, a inserção no comércio internacional (SCHULTER; VIEIRA FILHO, 2017).

A atividade da pesca é baseada no extrativismo e no uso dos recursos naturais sem o devido planejamento, já a aquicultura é a atividade controlada pelo homem com o objetivo de exploração produtiva econômica e financeira. A produção de pescado, que por muitos anos teve sua origem da pesca que passa por uma estagnação, sobretudo pela exploração dos estoques pesqueiros, encontrou na aquicultura a saída para a continuidade do crescimento sustentável (SCHULTER; VIEIRA FILHO, 2017).

O cultivo de peixes em tanques-rede pode não apenas aumentar a produção de pescados a nível nacional, mas também, criar condições para atrair novos investidores e tornar-se uma alternativa para a geração de emprego e renda, diminuindo assim a pressão sobre os estoques pesqueiros naturais. (AYROSA et al. 2005). Sendo a tilápia a principal espécie cultivada em tanques-rede no país. Estudos realizados por Kubtiza (2011) mostram que quando criadas em tanques-rede, as tilápias apresentam um alto índice de desempenho, sendo que sua biomassa pode atingir $480 \mathrm{~kg} / \mathrm{m} 3 \mathrm{em}$ tanques de $4 \mathrm{~m} 3$. 
Desta forma, pode-se relatar que a criação de peixes, nos sistemas semi-intensivos demanda investimentos significativos. Assim, sempre que algum investidor desejar apostar nesta atividade deve-se levar em consideração a viabilidade do negócio. Portanto, esse trabalho visou analisar a viabilidade econômica do cultivo de Tilápia do Nilo em um sistema de produção semiintensivo em uma propriedade no interior do noroeste do Rio Grande do Sul.

\section{PISCICULTURA COMO OPORTUNIDADE DE RENDA FAMILIAR}

Senar (2005) afirma que muitos produtores identificam na piscicultura uma fonte alternativa de subsistência e agregação de renda. Visto que a criação de peixes pode ser feita em pequenas dimensões de área alagada, com destinação a atender ao consumo e a renda familiar do produtor, obtendo uma carne de alta qualidade e baixo custo de produção (BARCELLOS; FAGUNDES, 2012).

Para tanto SEBRAE (2015), enfatiza que as pequenas propriedades rurais que atuam na cadeia produtiva do pescado, necessitam buscar diferentes maneiras para atender novos mercados, mantendo assim, o padrão de qualidade e a sanidade necessária para atender à crescente demanda. E para Kubitza e Ono (2010):

A criação de peixes em pequenas propriedades rurais contribui para o melhor aproveitamento dos recursos disponíveis, gera receita adicional com a comercialização de parte da produção, contribuindo para o bem-estar das famílias e incrementa a qualidade nutricional da dieta familiar, provendo uma opção a mais de lazer, a pescaria.

Ao contrário da produção agrícola "[...] a aquicultura é uma fonte de alimento mais previsível e constante, disponível o ano todo" (KUBITZA; ONO, 2010, p. 14). Com isso, Ostrensky e Boeger, (1998, p. 13), demonstram quais são os componentes básicos para iniciar a piscicultura comercial (Figura 1).

Figura 1- Componentes básicos de uma piscicultura comercial

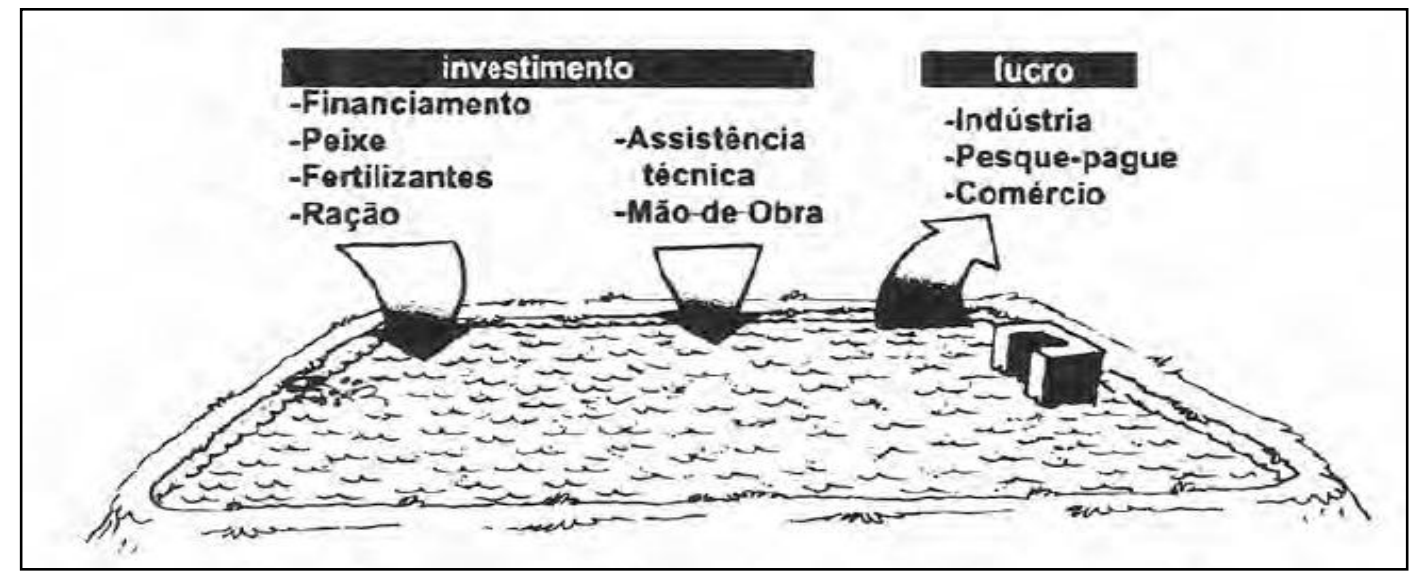

Fonte: (OSTRENSKY; BOEGER, 1998, p. 13). 
Como pode ser observado na figura 1, o processo de comercialização de tilápias começa a partir do investimento em comprar as tilápias, fertilizantes e ração, adquirir custeio para as despesas, contratação de mão de obra e assistência técnica, e entre outras atividades. O que a curto prazo não trará retorno, somente depois de 5 a 10 anos, quando os peixes forem encaminhados para a indústria, pesque-pague, comércio e consumidor final.

\subsection{Cultivo de tilápias}

A produção mundial de pescado em 2014 atingiu a marca de 167 milhões de toneladas, com 73,8 milhões provenientes da aquicultura (SCHULTER; VIEIRA FILHO 2017). O Chile registrou uma produção de 1,2 milhão de toneladas, seguido pelo Brasil, com 561 mil toneladas (ocupando a 13a posição no ranking geral dos maiores produtores de pescado). Na produção nacional, o Nordeste apresentou a maior participação de mercado no país, com 26,8\% (sendo Ceará o principal destaque). Logo após veio a região Norte, com 25,7\% (com Rondônia, que é o maior produtor nacional); a região Sul, com $24,2 \%$ (concentrando a produção no Paraná e em Santa Catarina); a região Centro-Oeste, com 12,6\% (principalmente por Mato Grosso); e o Sudeste, com 10,7\% de relevância na produção de São Paulo e de Minas Gerais (IBGE, 2016).

A tilápia do Nilo (Oreochromisniloticus) tem sido a espécie mais utilizada nos criatórios do Brasil, por sua excelente performance com o ganho de peso e crescimento, sua carne de qualidade superior e com poucas espinhas, o que ajuda na hora da filetagem (FIGUEIREDO; VALENTE, 2008). Correspondente a um percentual de 43,1\% da produção de peixes no Brasil, seguida pelo Tambaqui com 22,6\% e pelo grupo de Tambacu e Tambatinga com 15,4\% (IBGE, 2013).

Tabela 1 - Produção de Tilápias no período de 01.01 .2013 a 31.12.2013 e participações relativa e acumulada no total da produção, segundo as Unidades da Federação em ordem decrescente 2013.

(Continua)

Unidades da Federação

\begin{tabular}{ccccc} 
& & (Toneladas) & & \\
\cline { 3 - 4 } & & & Relativa & Acumulada \\
\hline $\mathbf{1}$ & Paraná & 44748 & 26,4 & 26,4 \\
\hline $\mathbf{2}$ & Ceará & 30634 & 18,1 & 44,5 \\
\hline $\mathbf{3}$ & São Paulo & 24329 & 14,4 & 58,9 \\
\hline $\mathbf{4}$ & Santa Catarina & 16472 & 9,7 & 68,6 \\
\hline $\mathbf{5}$ & Minas Gerais & 14329 & 8,5 & 77,1 \\
\hline $\mathbf{6}$ & Bahia & 8197 & 4,8 & 81,9 \\
\hline $\mathbf{7}$ & Goiás & 7371 & 4,4 & 86,3 \\
\hline $\mathbf{8}$ & Espírito Santo & 6289 & 3,7 & 90 \\
\hline $\mathbf{9}$ & Pernambuco & 3094 & 1,8 & 91,8 \\
\hline $\mathbf{1 0}$ & Mato Grosso do Sul & 2794 & 1,7 & 93,5 \\
\hline
\end{tabular}

Participação no total da produção

(\%) 
Tabela 1 - Produção de Tilápias no período de 01.01.2013 a 31.12.2013 e participações relativa e acumulada no total da produção, segundo as Unidades da Federação em ordem decrescente 2013.

(Conclusão)

Unidades da Federação

\begin{tabular}{lcccc} 
& & (Toneladas) & & \\
\cline { 3 - 4 } & & Relativa & Acumulada \\
\hline $\mathbf{1 1}$ & Rio Grande do Sul & 2330 & 1,4 & 94,9 \\
\hline $\mathbf{1 2}$ & Rio Grande do Norte & 2230 & 1,3 & 96,2 \\
\hline $\mathbf{1 3}$ & Sergipe & 1374 & 0,8 & 97 \\
\hline $\mathbf{1 4}$ & Paraíba & 952 & 0,6 & 97,5 \\
\hline $\mathbf{1 5}$ & Rio de Janeiro & 887 & 0,5 & 98,1 \\
\hline $\mathbf{1 6}$ & Distrito Fedreal & 800 & 0,5 & 98,5 \\
\hline $\mathbf{1 7}$ & Maranhão & 774 & 0,5 & 99 \\
\hline $\mathbf{1 8}$ & Piauí & 600 & 0,4 & 99,3 \\
\hline $\mathbf{1 9}$ & Mato Grosso & 559 & 0,3 & 99,7 \\
\hline $\mathbf{2 0}$ & Alagoas & 249 & 0,1 & 99,8 \\
\hline
\end{tabular}

Fonte: (IBGE, 2013).

Para Kubitza (2012), a piscicultura no Rio Grande do Sul aglomera o principal polo nos municípios de Ijuí e Ajuricaba, no qual existem cerca de 600 piscicultores que produzem entorno de 900 toneladas de peixe, que resulta em 1,5 tonelada/ano por produtor. A piscicultura, nesses municípios é caracterizada pelas espécies de Carpa, Tilápia e Jundiá que são escoados para os estados de Santa Catarina, Paraná e São Paulo. Diante disso, Figueiredo e Valente (2008, p.06) destacam que:

A maior parte da tilápia hoje produzida é comercializada nas propriedades diretamente com o consumidor final. O processamento, quando feito, é realizado em escala reduzida, em frigoríficos de pequeno porte, apesar de já ser perceptível nos últimos anos a tendência de crescimento do número de frigoríficos que processam o peixe (FIGUEIREDO; VALENTE, p. 06).

Planejamento de controle dos custos e das receitas, passa a ser uma ferramenta importante na piscicultura, pois, auxilia os piscicultores a avaliar as tecnologias utilizadas na produção e avaliar alternativas que assegurem a viabilidade econômica do investimento (VILELA et al, 2013). Por exemplo, para SENAR (2005), a construção de tanques, compra dos alimentadores, entre outros, são considerados investimentos porque podem ser utilizados a longos períodos e consequentemente darão um retorno. Portanto, "diversas são as técnicas de análise de viabilidade econômica de investimentos, contudo todas têm um único objetivo: auxiliar na tomada de decisão de investir ou não no projeto" (VILELA et al., 2013, p. 158).

Este projeto trata-se de um plano financeiro e estratégico ao longo prazo, por se tratar de um investimento previsto para um período de cinco a dez anos. Dessa forma, um bom planejamento financeiro é de fundamental importância para qualquer atividade desenvolvida, 
visto que o valor a ser investido, antes de tudo deve ser analisada a viabilidade econômica do negócio.

\section{METODOLOGIA}

Este estudo foi realizado em uma empresa rural, situada na cidade de Derrubadas no noroeste do estado do Rio Grande do Sul. A propriedade rural atua no setor agropecuário, a qual opera na agricultura com produção de grãos sendo soja, milho e trigo e na pecuária atua na criação de gado de corte; e com a criação de peixes da espécie Tilápia do Nilo para engorda e abate. As atividades no setor agropecuário deram início no ano de 1985, e na piscicultura no ano de 2014. A propriedade rural conta com aproximadamente 23 hectares, com três açudes para a criação de Tilápias do Nilo. Um dos tanques já existia na propriedade desde seu início, nos anos de 1985 e nos últimos dois anos a propriedade realizou alguns investimentos, como na escavação de dois novos açudes, limpeza do existente, fabricação artesanal de um aerador, compra de um novo aerador e fabricação artesanal de um tratador automático.

A empresa rural conta com dois proprietários responsáveis para o cuidado das tilápias, entre elas a alimentação, a oxigenação da água e manutenções. Possui também três servidores temporários (empregados) para épocas de despesca, que ocorre quando os peixes já estão no peso ideal para o abate e com o auxílio de um técnico que presta assessoria direta a propriedade, que faz parte da empresa fornecedora de ração.

Esta pesquisa caracteriza-se como exploratória e para acompanhar as atividades realizadas na propriedade melhorando a obtenção de experiências diretas com a situação estudada, foi realizada uma pesquisa de campo. Os dados coletados referem-se ao levantamento dos custos e receitas, para elaboração dos cálculos e análises de viabilidade. Assim faz-se a mesma, a partir do uso de fórmulas para o cálculo dos seguintes indicadores: Valor Presente Líquido, Payback, Taxa interna de retorno e Índice de Lucratividade.

\subsection{Fluxo De Caixa}

O fluxo de caixa é importante para decisão de um investimento, pois é com ele que a empresa deve observar como se comporta os fluxos de entradas e saídas, assim o fluxo se dá a partir das receitas menos despesas. A estimativa dos fluxos de caixa consiste no ponto de partida do orçamento de capital, o mesmo será avaliado sobre aplicação das técnicas simples como prazo de retorno ou do valor atual líquido e taxa interna de retorno (BRAGA, 2010). Nessas perspectivas, “devem ser computados apenas os pagamentos e recebimentos adicionais que serão 
provocados pela implantação da proposta. Isto significa que apenas os fluxos de caixa incrementais serão avaliados" (BRAGA, 2010, p. 279).

O que não sofrer variação por razão da tomada de decisão do investimento, não proporciona algum interesse para o dimensionamento do fluxo de caixa, apenas se tornam relevantes os que se alteram em uma proposta de investimento, ou seja, os valores que não se alteram são desconsiderados, pois não influenciarão os resultados (ASSAF NETO, 2010).

Galesne (1999, p. 39) afirma que os fluxos de caixa descontados têm duas importantes características: "por um lado, supõem a consideração de todos os fluxos de caixa (positivos e negativos) associados a determinados projetos de investimento ao longo de toda vida útil e por outro lado, princípio de desconto".

E pode ser representada através da fórmula:

$$
\frac{F C}{(1+k)}
$$

Onde:

$\mathrm{K}=$ Taxa de desconto ou taxa mínima de atratividade (TMA)

De acordo com o mesmo autor, a taxa de desconto $\mathrm{K}$, representa uma taxa de juros a qual faz com que $\mathrm{R} \$ 1,00$ hoje, seja igual a $(1+\mathrm{K})$ reais em ano. Conforme, ilustrado na fórmula acima.

\subsection{Tempo De Retorno Do Investimento (PAYBACK)}

O Payback tem a capacidade de determinar o tempo de retorno de um investimento, ou seja, é o cálculo realizado a fim de descobrir quanto tempo é necessário para que os valores aplicados retornem. Barcellos e Fagundes (2012, p. 127) conceituam o tempo de retorno do investimento como "quando será recuperado o investimento realizado, ou seja, em quanto tempo (meses ou anos) o dinheiro investido retornará".

Para Braga (2010), quanto maior for o tempo determinado para o retorno, consequentemente será maior o grau de incertezas, se determinarem um tempo mais curto este terá maior liquidez e assim, menor risco. No Payback não existe um tempo determinado entre mínimo e máximo que seja preestabelecido, porque poderá variar de qual o ramo de negócio estabelecido e o montante investido. Para o cálculo do Payback será realizado uma análise do fluxo de caixa e quando as entradas (receitas) forem maiores que as saídas (fluxos negativos) haverá o Payback (BARCELLOS; FAGUNDES, 2012).

O Payback pode ser "calculado dividindo-se o valor do investimento inicial pela média do fluxo de caixa anual [...], o Payback é utilizado juntamente com os métodos do VPL e TIR no 
processo de tomada de decisão" (BARCELLOS; FAGUNDES, 2012, p. 127). O Payback pode ser calculado usando a seguinte fórmula:

$$
\text { Payback }=\frac{\text { Investimento Inicial }}{\text { Média do fluxo anual }}
$$

Geralmente se considera o Payback descontado, ou seja, já considerado uma taxa de desconto (TMA) para o investimento em análise. Conforme, exemplificado na fórmula acima.

\subsection{Valor Presente Líquido (VPL)}

O Valor presente líquido (VPL) está entre as ferramentas mais utilizadas para avaliação de investimentos de capital. Nessas situações o investimento é medido pela diferença entre o valor das entradas de caixa e o valor das saídas de caixa, a uma taxa de desconto. Só é viável o investimento, se o valor presente líquido for igual ou maior a zero (BARCELLOS; FAGUNDES, 2012).

Segundo Gitman (2004, p.342), o VPL "Leva explicitamente em conta o valor do dinheiro no tempo, é considerado uma técnica sofisticada de orçamento de capital. Todas essas técnicas descontam, de uma maneira ou de outra, os fluxos de caixa de uma empresa a uma taxa estipulada." Esta análise do custo de capital, consiste em descontar os caixas futuros, quando foR positivo, será aceito, ao contrário de um fluxo de caixa negativo, o qual será rejeitado (BARCELLOS; FAGUNDES, 2012).

Para Barcellos e Fagundes (2012, p.124), “um VPL positivo indica que o capital investido será recuperado, remunerado na taxa de juros que mede o custo de capital do projeto, e gerará um ganho extra na data zero, igual ao VPL”. E também, determinam o VPL como um excelente método para determinação de um investimento, ele representa o total de retorno líquido gerado pelo projeto.

Destarte, o Valor presente líquido é ilustrado conforme a fórmula a seguir (BARCELLOS; FAGUNDES, 2012):

Onde:

$$
\mathrm{VPL}=\sum_{j=1}^{n} \frac{C F_{j}}{(j+i)^{j}}-F C_{0}
$$

$\mathrm{FC}_{0}=$ investimento inicial

$\mathrm{FC}_{j}=$ valor presente das entradas de caixa

$\mathrm{I}=$ taxa de custo de capital 


\subsection{Taxa Interna De Retorno (TIR)}

A TIR significa a taxa de rentabilidade periódica de um projeto de investimento. Para Braga (2010, p. 290), “corresponde a uma taxa de descontos que iguala o valor atual das entradas líquidas de caixa ao valor atual dos desembolsos relativos a investimento líquido".

É umas das formas mais adequadas para avaliar sugestões de investimentos, mostrando a rentabilidade média do valor aplicado no projeto durante todo o seu período de existência (BARCELLOS; FAGUNDES, 2012). Essa taxa também pode ser considerada com uma taxa de rentabilidade mínima exigida do risco de projeto, a taxa mínima também representa o custo de capital da empresa (BRAGA, 2010).

A TIR "é a taxa que torna nulo o VPL do fluxo de caixa do investimento [...]" (BARCELLOS; FAGUNDES, 2012, p. 125). Pois ela é a taxa que torna os valores dos lucros equivalentes aos gastos para inicialização do projeto, também conhecida como a taxa de remuneração do capital.

Só é possível considerar um investimento viável, se a TIR for maior do que a Taxa Mínima de Atratividade (TMA), porque ela torna igual a zero o Valor Presente Líquido, sendo assim é uma das formas mais completas para a análise de um investimento de capital (BARCELLOS; FAGUNDES, 2012). As condições de viabilidade de projeto só poderão acontecer se a TIR for maior que a TMA, o projeto é economicamente viável; se a TIR for menor que TMA, o projeto não é viável; e se a TIR for igual a TMA, torna-se indiferente fazer esse investimento.

A TIR pode ser expressa pela seguinte formula matemática:

$$
\$ 0=\sum_{t=1}^{n} \frac{F C_{t}}{(1+T I R)^{t}}-F C_{0}
$$

Onde:

$F C_{0}=$ investimento inicial

$\mathrm{FC}_{t}=$ valor presente das entradas de caixa

\section{4 Índice de Lucratividade}

Conforme Braga (2010), o índice de lucratividade (IL) ou índice de rentabilidade do projeto, é calculado por meio do quociente dos valores atuais dos fluxos de entrada e saída de caixa. Assim, temos: 
Índice de Lucratividade $=\underline{\text { Valor atual das entradas líquidas de caixa }}$, ou Valor atual das saídas líquidas de caixa

$$
\frac{\sum_{j=1}^{n} \frac{E_{j}}{(1+i)^{j}}}{I_{0}+\sum_{j=1}^{n} \frac{I_{j}}{(1+i)^{j}}}
$$

Onde:

$\mathrm{E}_{\mathrm{j}}=$ cada uma das entradas líquidas de caixa

$\mathrm{I}_{0}=$ valor do investimento no momento $t_{0}$

$\mathrm{I}_{\mathrm{j}}=$ saídas líquidas de caixa nos períodos subsequentes

I = taxa de desconto atualizada

$\mathrm{J}=$ período de ocorrência dos fluxos de caixa

$\mathrm{n}=$ total de períodos do projeto

Braga (2010), afirma que este índice faz uma análise do "custo/benefício" do projeto e fornece uma medida de retorno esperado por unidade monetária. Assim, foram levantados os custos e receitas referentes a produção de Tilápias do Nilo no ano de 2015 da propriedade, e calculados esses indicadores para identificar se a produção de tilápias é viável. Para efeitos de análise de viabilidade econômica, embora os dados sejam reais de uma atividade já em andamento, considerou-se como se o projeto estivesse em implantação, conforme dados apresentados na próxima seção.

\section{RESULTADO}

Os gastos anuais com mão de obra, conforme apresentados na Tabela 2, incluem os proprietários e os empregados "temporários" para os dias de despesca. Sendo, considerado 45 minutos de trabalho por dia para os proprietários responsáveis pelo cuidado com as tilápias, entre eles: a alimentação, cuidado com a oxigenação da água e manutenções. O tempo para a produção de tilápias é de aproximadamente oito meses (um ciclo por ano na região sul), porque no inverno as tilápias pouco se alimentam. Assim, soma-se a mão de obra diária, com dois dias para despesca, quando ocorre a contratação de três trabalhadores.

Tabela 2-Quadro de funcionários

\begin{tabular}{|c|c|c|c|c|}
\hline Mão de obra & $\mathbf{N}^{\mathbf{o}}$ de pessoas & Período/ mês & Remuneração mensal & Custo anual \\
\hline Proprietário & 2 & 12 Meses & $\mathrm{R} \$ 100,00$ & $\mathrm{R} \$ 2.400,00$ \\
\hline Temporários & 3 & 2 Dias & $\mathrm{R} \$ 100,00$ & $\mathrm{R} \$ 600,00$ \\
\hline & & & Total & $\mathbf{R} \$ \mathbf{3 . 0 0 0 , 0 0}$ \\
\hline
\end{tabular}

Fonte: Elaborado pelos autores. 
Os gastos anuais com mão de obra totalizam $\mathrm{R} \$ 3.000,00$. Sendo, $\mathrm{R} \$ 100,00$ por funcionário temporário para cada dia de despesca e $\mathrm{R} \$ 100,00$ por mês para cada um dos proprietários, em um período de doze meses, totalizando $\mathrm{R} \$ 2.400,00$.

Tabela 3 - Custeio anual financiado

\begin{tabular}{|c|c|c|c|c|}
\hline Parcela & Saldo devedor & Amortização & Juros & Valor Total Anual \\
\hline $\mathbf{1}$ & $\mathrm{R} \$ 30.000,00$ & $\mathrm{R} \$ 30.000,00$ & $\mathrm{R} \$ 1.200,00$ & $\mathrm{R} \$ 31.200,00$ \\
\hline & $\begin{array}{c}\text { Juros do } \\
\text { financiamento }\end{array}$ & $4 \%$ & Total & $\mathbf{R} \$ \mathbf{3 1 . 2 0 0 , 0 0}$ \\
\hline
\end{tabular}

Fonte: Elaborado pelos autores.

Anualmente é realizado um financiamento de custeio para a aquisição de alevinos e a alimentação dos mesmos. Este custeio no valor de $\mathrm{R} \$ 30.000,00$ possui taxa de $4 \%$ a.a. proveniente de recurso Pronaf.

Tabela 4 - Despesas para produção anual

\begin{tabular}{|c|c|}
\hline \multicolumn{2}{|c|}{ Despesas para produção anual } \\
\hline Itens: & Valores (R\$) \\
\hline Mão de obra & $\mathrm{R} \$ 3.000,00$ \\
\hline Ração & $\mathrm{R} \$ 36.000,00$ \\
\hline Energia elétrica & $\mathrm{R} \$ 700,00$ \\
\hline Alevinos & $\mathrm{R} \$ 2.210,00$ \\
\hline Total & $\mathbf{R} \$ \mathbf{4 1 . 9 1 0 , 0 0}$ \\
\hline
\end{tabular}

Fonte: Elaborado pelos autores.

Para a produção anual são gastos $\mathrm{R} \$ 41.910,00$ dentre eles estão os custos com mão de obra ( $\mathrm{R} \$ 3.000,00)$, os quais são necessários três funcionários temporários e os proprietários; energia elétrica $(\mathrm{R} \$ 700,00)$ para o funcionamento dos aeradores e tratador; já para os gastos com ração e alevinos são pagos através de financiamento e recursos próprios, os valores gastos com ração completam $\mathrm{R} \$ 36.000,00$ (o que resultou em um total de 800 sacas a um valor unitário de $\mathrm{R} \$ 45,00)$ e para a compra de alevinos absteve-se um gasto de $\mathrm{R} \$ 2.210,00$. Somando-se o gasto com ração e alevinos resultou em um total de $\mathrm{R} \$ 38.210,00$.

O financiamento foi de $\mathrm{R} \$ 30.000,00$ a uma taxa de juros de $4 \%$ a.a., apenas cobriu uma parte dos gastos com ração e alevinos, o restante dos gastos foram pagos com recursos próprios. Assim, obteve-se um gasto de $\mathrm{R} \$ 2.210,00$ para alevinos e $\mathrm{R} \$ 6.000,00$ com ração, o qual somado gerou um valor de $\mathrm{R} \$ 8.210,00$. Portanto, o valor do financiamento com os gastos próprios resultou em um montante de $\mathrm{R} \$ 38.210,00$. 
Os custos de aquisição de alevinos, ração e energia elétrica estão baseados em uma produção de $12.000 \mathrm{~kg}$ de peso vivo de tilápia, conforme o Tabela 5.

Tabela 5 - Produção Anual

\begin{tabular}{|c|c|}
\hline \multicolumn{2}{|c|}{ Produção Anual } \\
\hline Quant. Alevinos & 17.000 \\
\hline Quant. Vend. Peso vivo / Kg & 12.000 \\
\hline Preço de venda Unit. R\$ & $\mathrm{R} \$ 4,20$ \\
\hline Total & $\mathbf{R} \mathbf{5 0 . 4 0 0 , 0 0}$ \\
\hline
\end{tabular}

Fonte: Elaborado pelos autores.

No ano de 2015, foram gastos com a produção de tilápias 800 sacas de ração num custo $\mathrm{R} \$ 45,00$ a unidade e 17.000 alevinos a $\mathrm{R} \$ 0,13$ cada. Já, em relação a quantidade vendida em peso vivo para caminhões que transportam carga viva foram $12.000 \mathrm{~kg}$, a um preço de venda de $\mathrm{R} \$ 4,20$, obtendo uma receita bruta de $\mathrm{R} \$ 50.400,00$.

Tabela 6 - Investimento

\begin{tabular}{|c|c|}
\hline \multicolumn{2}{|c|}{ Investimento } \\
\hline Investimento & Valor \\
\hline Açude 1 & $\mathrm{R} \$ 4.600,00$ \\
\hline Açude 2 & $\mathrm{R} \$ 8.320,00$ \\
\hline Açude 3 & $\mathrm{R} \$ 6.720,00$ \\
\hline Aerador comprado & $\mathrm{R} \$ 1.800,00$ \\
\hline Aerador artesanal & $\mathrm{R} \$ 500,00$ \\
\hline Tratador artesanal & $\mathrm{R} \$ 500,00$ \\
\hline Local de armazenagem de Ração & $\mathrm{R} \$ 500,00$ \\
\hline Total & $\mathbf{R} \$ \mathbf{2 2 . 9 4 0 , 0 0}$ \\
\hline
\end{tabular}

Fonte: Elaborado pelos autores.

No caso do açude 1 já existente na propriedade houve a necessidade de realizar manutenção. Os demais açudes ( 2 e 3 ) e os equipamentos foram investimentos realizados com o objetivo de implantar o sistema semi-intensivo de criação de tilápias para comercialização. $\mathrm{O}$ total de investimentos para iniciar a atividade comercial foi de $\mathrm{R} \$ 22.940,00$.

Os custos com esses equipamentos totalizam $\mathrm{R} \$ 3.300,00$ todos depreciados em dez anos, Tabela 7. Um dos equipamentos que mais custaram foi aerador comprado, ao passo que para o aerador e tratador artesanal foram utilizadas peças que estavam sem uso na propriedade e algumas peças compradas, os gastos com equipamentos artesanais foram estipulados pelo dono da propriedade. 
Tabela 7 - Depreciação

\begin{tabular}{|l|l|l|lr|}
\hline \multicolumn{1}{|c|}{ Período } & Equipamento e Imóveis & \multicolumn{2}{c|}{ Açude } & \multicolumn{2}{c|}{ Total } \\
\hline $\mathbf{1}$ & 330,00 & $1.964,00$ & $\mathrm{R} \$$ & $2.294,00$ \\
\hline $\mathbf{2}$ & 330,00 & $1.964,00$ & $\mathrm{R} \$$ & $2.294,00$ \\
\hline $\mathbf{3}$ & 330,00 & $1.964,00$ & $\mathrm{R} \$$ & $2.294,00$ \\
\hline $\mathbf{4}$ & 330,00 & $1.964,00$ & $\mathrm{R} \$$ & $2.294,00$ \\
\hline $\mathbf{5}$ & 330,00 & $1.964,00$ & $\mathrm{R} \$$ & $2.294,00$ \\
\hline $\mathbf{6}$ & 330,00 & $1.964,00$ & $\mathrm{R} \$$ & $2.294,00$ \\
\hline $\mathbf{7}$ & 330,00 & $1.964,00$ & $\mathrm{R} \$$ & $2.294,00$ \\
\hline $\mathbf{8}$ & 330,00 & $1.964,00$ & $\mathrm{R} \$$ & $2.294,00$ \\
\hline $\mathbf{9}$ & 330,00 & $1.964,00$ & $\mathrm{R} \$$ & $2.294,00$ \\
\hline $\mathbf{1 0}$ & 330,00 & $1.964,00$ & $\mathrm{R} \$$ & $2.294,00$ \\
\hline
\end{tabular}

Fonte: Elaborado pelos autores.

Os dados apresentados na Tabela 7 acima representam a depreciação dos equipamentos e imóveis, juntamente com os açudes, totalizando um valor depreciado anualmente de $\mathrm{R} \$ 2.294,00$. Já para o período de dez anos, o valor acumulado foi $\mathrm{R} \$ 22.940,00$. Após o levantamento dos custos, dos investimentos, da depreciação e das receitas foi possível elaborar o fluxo de caixa, conforme Tabela 8 .

Tabela 8 - Fluxo de Caixa

\begin{tabular}{|c|c|c|c|c|c|c|}
\hline Período & Receitas & $\begin{array}{c}\text { Despesas } \\
\text { Custos }\end{array}$ & Fluxo & $\begin{array}{c}\text { Fluxo } \\
\text { Acumulado }\end{array}$ & $\begin{array}{c}\text { Fluxo } \\
\text { Descontado }\end{array}$ & $\begin{array}{c}\text { Fluxo } \\
\text { Acumulado } \\
\text { Descontado }\end{array}$ \\
\hline $\mathbf{0}$ & - & - & $-\mathbf{2 2 . 9 4 0 , 0 0}$ & - & $\mathbf{- 2 2 . 9 4 0 , 0 0}$ & \\
\hline $\mathbf{1}$ & $50.400,00$ & $44.204,00$ & $6.196,00$ & $-16.744,00$ & $5.387,83$ & $-17.552,17$ \\
\hline $\mathbf{2}$ & $50.400,00$ & $44.204,00$ & $6.196,00$ & $-10.548,00$ & $4.685,07$ & $-12.867,11$ \\
\hline $\mathbf{3}$ & $50.400,00$ & $44.204,00$ & $6.196,00$ & $-4.352,00$ & $4.073,97$ & $-8.793,14$ \\
\hline $\mathbf{4}$ & $50.400,00$ & $44.204,00$ & $6.196,00$ & $1.844,00$ & $3.542,58$ & $-5.250,55$ \\
\hline $\mathbf{5}$ & $50.400,00$ & $44.204,00$ & $6.196,00$ & $8.040,00$ & $3.080,51$ & $-2.170,05$ \\
\hline $\mathbf{6}$ & $50.400,00$ & $44.204,00$ & $6.196,00$ & $14.236,00$ & $2.678,70$ & 508,65 \\
\hline $\mathbf{7}$ & $50.400,00$ & $44.204,00$ & $6.196,00$ & $20.432,00$ & $2.329,31$ & $2.837,96$ \\
\hline $\mathbf{8}$ & $50.400,00$ & $44.204,00$ & $6.196,00$ & $26.628,00$ & $2.025,48$ & $4.863,44$ \\
\hline $\mathbf{1 0}$ & $50.400,00$ & $44.204,00$ & $6.196,00$ & $32.824,00$ & $1.761,29$ & $6.624,73$ \\
\hline
\end{tabular}

Fonte: Elaborados pelos autores.

Pode-se observar que o fluxo é positivo, ou seja, a receita anual prevista supera as despesas. Ao acumular este fluxo positivo, quando o valor do investimento passa a ser considerado, verifica-se que entre o terceiro e quarto período há a recuperação do investimento (Payback Simples).

No entanto, há que se considerar o dinheiro no tempo, para tanto estabeleceu-se para o referido projeto uma TMA de $15 \%$ ao ano, que seria a mínima taxa aceita de remuneração do projeto. Assim, é possível constituir o fluxo descontado e o fluxo acumulado descontado. 
Pelo fluxo acumulado descontado qual considera o dinheiro no tempo a uma taxa de $15 \%$ tem-se a recuperação do investimento (Payback Descontado) entre o quinto e sexto período. Os índices que foram utilizados nessa análise da viabilidade econômica para a criação de Tilápias do Nilo, descritos na metodologia estão na tabela 9.

Tabela 9 - Índices de viabilidade

\begin{tabular}{|c|c|}
\hline Índices & Valor \\
\hline Investimento & $\mathrm{R} \$ 22.940,00$ \\
\hline TMA & $15 \%$ \\
\hline Índice De Lucratividade & $\mathrm{R} \$ 1,36$ \\
\hline VPL Unitário & 0,36 \\
\hline Payback Descontado & 5 anos 8 meses \\
\hline VPL & $\mathrm{R} \$ 8.156,29$ \\
\hline TIR & $27 \%$ \\
\hline
\end{tabular}

Fonte: Elaborado pelos autores.

O valor do investimento é o resultado da soma dos valores dos gastos com escavação e limpeza dos açudes mais o valor total dos equipamentos e imóveis, obtendo-se um valor total de R\$ 22.940,00. Já, a Taxa Mínima de Atratividade (TMA), é o uma taxa definida pela empresa e que significa o mínimo que o proprietário se propõe a ganhar ao fazer um investimento, neste projeto foi definido uma TMA de $15 \%$.

Para chegar ao Índice de lucratividade deve-se somar os valores do fluxo descontado dividindo o mesmo pelo valor do investimento inicial. Resultando em um valor de $\mathrm{R} \$ 1,36$ conclui-se que para cada unidade monetária investida ocasionará em um retorno de $\mathrm{R} \$ 1,36$, ou seja, $\mathrm{R} \$ 1,00$ para pagar o investimento e os restantes $\mathrm{R} \$ 0,36$ de sobra (lucro).

Para tanto, o Valor Presente Líquido Unitário de R\$ 0,36, é resultante da divisão VPL pelo valor do investimento Inicial de R $\$ 22.940,00$. Ou seja, o VPL avalia a mudança de valor do dinheiro no tempo, os fluxos de caixas são trazidos para valores presentes e descontando uma taxa de juros (neste caso 15\%), e finalizando diminuindo o valor do investimento inicial. Desta forma este projeto irá pagar o investimento de $\mathrm{R} \$ 22.940,00$ e ainda resultará em uma sobra de $\mathrm{R} \$ 8.156,29$. Assim, este investimento deverá ser aceito, segundo este índice, pois, resultará em lucro para a empresa após o período considerado.

A TIR demostra a taxa que torna o VPL nulo, esta taxa apresenta um valor esperado acima da TMA, estipulada pela empresa de $15 \%$. O que resulta em uma TIR de $27 \%$, valor este bem elevado tendo em vista do tipo de investimento, tornando-o viável também.

Para o cálculo do Payback descontado na Tabela 8, foi utilizado o último período do fluxo descontado que é negativo no período 5 da Tabela 7, o qual foi dividido pelo fluxo do período 6 . 
Assim, o Payback resultou em 5 anos e 8 meses, logo após esse tempo, o projeto começou a ter retorno sobre o valor investido.

Nos cálculos a depreciação foi incluída no fluxo de caixa e ao final de 10 anos este projeto geraria remuneração suficiente para refazer o investimento realizado neste momento. Para tanto, a depreciação não se caracteriza como um desembolso, e sim, consiste em um provisionamento contábil para repor o montante em bens investidos na propriedade.

Portanto, ao fim das análises dos resultados, conclui-se que o projeto da criação de Tilápias do Nilo tem viabilidade econômica. Pois, este projeto trouxe bons resultados para todos os índices calculados, tanto o VPL e a TIR resultaram em valores significativos, o que representa que este projeto remunerará mais que a taxa mínima esperada pela propriedade rural.

\section{CONCLUSÃO}

O cultivo de Tilápias do Nilo em sistemas semi-intensivos apresentou-se viável, em função da tilápia estar cada vez mais presente na mesa do consumidor. E também, por obter resultados econômicos positivos, retorno rápido e lucratividade, os quais impulsionam a cadeia como um todo. Da mesma forma que alavancam as atividades da aquicultura nas grandes e pequenas propriedades rurais.

Para tanto, os estudos por mais que sejam efetivados de maneira eficiente para busca da conclusão dos resultados, encontram limitações no decorrer da pesquisa. Neste trabalho, considerou-se a disposição de prazos como um limitador, em virtude do tempo ao qual não propiciou realizar o estudo em mais de uma propriedade rural.

Entretanto, vale destacar a importância do preciso estudo, ressaltando a proeminência de semelhantes estudos na temática. Indica-se, a realização de pesquisas futuras no sentido de oportunizar a construção de um estudo comparativo de duas ou mais propriedades. Assim, viabilizando um plano de gestão financeira nas propriedades rurais, com o intuito de assessorar o desenvolvimento da atividade da produção de Tilápia do Nilo, afim de obter uma visão futura da lucratividade com investimentos na área, além de estabelecer diretrizes para garantir o prosseguimento da propriedade no decorrer das gestões.

Destarte, almeja-se que os resultados desta pesquisa tenham utilidade para posteriores estudos e que possam servir como assistência na construção do conhecimento. Uma vez que a aquicultura constitui-se em um campo com potencialidades promissoras no mercado consumidor futuro. 


\section{REFERÊNCIAS}

ASSAF NETO, A. Finanças Corporativas e Valor. 5 ed. São Paulo: Atlas, 2010.

AYROZA, D. M. M. R; FURLANETO, F. P. B; AYROZA, L. M. S. Regulamentação do acesso territorial aos tanques-rede em área de preservação permanente - APP, no Estado de São Paulo.

Panorama da Aquicultura, Rio de Janeiro, n. 90, p. 63 - 65, 2005.

BARCELlOS, G. J. L.; FAGUNDES, M. (Org.) Policultivo de jundiás, tilápias e carpas: uma alternativa de produção para a piscicultura rio-grandense. 2 ed. Passo Fundo: Universidade de Passo Fundo, 2012.

BRAGA, R. Fundamentos e técnicas de administração financeira. São Paulo: Atlas, 2010.

FAO. O estado do mundo pescas e aquicultura: contribuindo para segurança alimentar e nutrição para todos. Roma, [s.n.], 2016.

FIGUEIREDO, JUNIOR, C. A.; VALENTE, JUNIOR. S. A. Cultivo de tilápias no Brasil: origens e cenário atual, 2008. Disponível em:

<http://www.sober.org.br/palestra/9/178.pdf>. Acesso em 24 de jun. de 2016

GALESNE, A.; FENSTERSEIFER, J. E.; LAMB, R. Decisões de investimentos da empresa. São Paulo: Atlas, 1999.

GITMAN, L. J. Princípios de Administração Financeira. 10 ed. São Paulo: Pearson Addison Wesley, 2004.

IBGE - Instituto Brasileiro de Geografia e Estatística. Produção da pecuária mundial, Rio de Janeiro, v.41, p.1 - 108, 2013.

IBGE- Instituto Brasileiro de Geografia e Estatística. Produção da pecuária municipal 2016, Rio de Janeiro, v.44, p.1 - 53, 2016.

KUBITZA, F. Tilápia: tecnologia e planejamento na produção comercial. 2. ed; Jundiaí: Kubitza, 2011.

KUBITZA, F. et. al. Panorama da piscicultura no Brasil, parte I estatísticas, espécies, polos de produção e fatores limitantes à expansão da atividade. Panorama da aquicultura, Jundiaí, v. 22, nº132, p. 16-20, Jul-ago. 2012.

KUBITZA, F. ONO, E. A. Piscicultura familiar: como ferramenta para o desenvolvimento e segurança alimentar no meio rural. Panorama da Aquicultura. v. 20, n. 117, jan./fev. 2010. Disponível em:

<http://www.acquaimagem.com.br/docs/Pan117_Kubitza_piscicultura_familiar.pdf $>$. Acesso 25 jun. 2016.

OSTRENSKY, A.; BOEGER, W. Piscicultura: fundamentos e técnicas de manejo. Guaíba: Agropecuária, 1998. 
SEBRAE. Piscicultura traz boas oportunidades para os produtores rurais. Disponível em: <http://www.sebrae.com.br/sites/PortalSebrae/artigos/piscicultura-traz-boas-oportunidades-paraos-produtores-rurais,63c81a5b6e00f410VgnVCM1000004c00210aRCRD>. Acessado em: 14 de dez. de 2016.

SENAR. Criação de peixe de água doce: manual do treinado. Porto Alegre, [s.n.], 2005.

SOUZA, D. I. de. et al. Manual de orientações para projetos de pesquisa. Novo Hamburgo: FESLSVC, 2013. 55 p. Disponível

em: <http://liberato.com.br/sites/default/files/manual_de_orientacoes_para_projetos_de_pesquisa. pdf $>$. Acesso em: 23 jun. 2016.

SCHULTER, E. P; VIEIRA FILHO, J.E.R. Evolução da piscicultura no brasil: diagnóstico e desenvolvimento da cadeia produtiva de tilápia. Instituto de Pesquisa Econômica Aplicada - ipea 2017. Disponível em: <http://repositorio.ipea.gov.br/bitstream/11058/8043/1/td_2328.pdf >. Acesso em 01 de jun. de 2019.

VILELA, C. M. et al. Análise da viabilidade econômico-financeira de projeto de piscicultura em tanques escavados, Goiás, v. 9, n. 3, p. 156-158, Jul-Set. - 2013. 